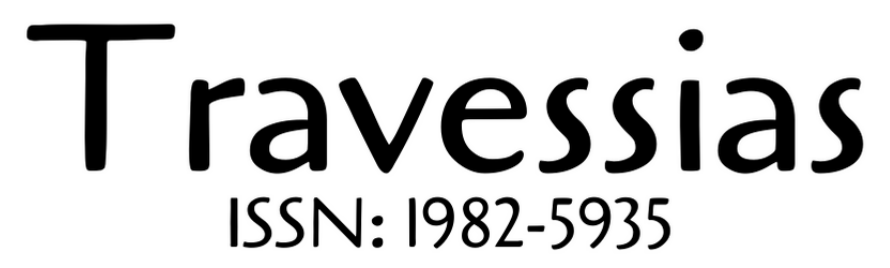

Direitos autorais distribuídos a partir da
licença Creative Commons (CC BY-NC-SA - 4.0)

\title{
APRESENTAÇÃO DA 43ª EDIÇÃO DA TRAVESSIAS
}

O mundo contemporâneo se caracteriza, cada vez mais, a adesão ao processo de secularização e desmistificação das atividades simbólicas. As zonas de não sentidos, de incomunicabilidade, são cada vez mais evidentes. Note-se por exemplo, a presença da memória na condição de mercadoria corrente no mundo das artes. A hibridização das mídias se torna um fenômeno tão evidente quanto natural e parece se caracterizar pela relação temporal de tudo aquilo que não foi resolvido no passado e que se deixa perceber por sua condição relacional no presente, ocultado, mas ainda sim latente.

A latência é o furo que faz emergir a condição recalcada do objeto. Posicionar-se diante de um objeto de arte significa estar diante de um corpo e sua história de modo anacrônico, ou seja, na acumulação de todos os tempos, vivificados, presentificados, reafirmados na intersecção de inúmeras mídias que se mesclam em feixes de sentidos quase sempre aleatórios.

Assim, a questão da primazia das intermídias na contemporaneidade reside na perda da referência divina, ou seja, a perda do sentido aurático das imagens. Enquanto a dissimulação põe em destaque a aparência do real, a simulação torna a imagem hiper-real. E é, nesse conceito, que as artes da hipermodernidade se manifestam. A representação difere da simulação, pois que aquela parte do princípio de equivalência do signo e do real, a outra não. Ela parte da negação radical do signo como valor, parte do signo como reversão e aniquilamento de toda referência. A representação tenta absorver a simulação interpretando-a como falsa representação, a simulação envolve todo o próprio edifício da representação como simulacro. Ela não tem qualquer relação com a realidade: ela é o seu próprio simulacro puro.

Partindo dessas questões, o volume 15, n. 2 da Travessias está organizada da seguinte forma: como artigos selecionados para a seção DOSSIÊ TEMÁTICO: LITERATURA, CINEMA E INTERMIDLALIDADE: TEXTOS, CONTEXTOS E IMAGENS, temos: Transposição midiática $e$ representação cultural em "Viva - a vida é uma festa" (2018), de Thiago Henrique da Silva de Sales e Líliam Cristina Marins; A presença constante da Segunda Guerra Sudanesa no filme O que ficou para trás (2020), de Carlos Eduardo de Araujo Placido; Labirintos autorais: a adaptação filmica de In the tall grass, de Stephen King e Joe Hill, de Edson José Rodrigues Júnior; O olhar através: o uso da câmera subjetiva indireta livre no cinema contemporâneo, de Fabiana Maceno Domingos Pedrolo; Representação e recordações da malandragem em Memórias de Madame Satã, de Sylvan Paezzo, de Victória Nantes Marinho Adorno e Andre Rezende Benatti; Teatro e intermidialidade: um estudo do espetáculo "Quando eu morrer vou contar tudo a Deus", de Lysiane Cassia Baldo; Mulheres de Joel Zito Araújo: subversão ou reproducão de estereótipos?, de Risoleta Viana de Freitas; A cosmicidade 
da casa: seus mitos e imagens no filme Mãe!, de Darren Aronofsky, de Adriano Menino de Macêdo Júnior e Roniê Rodrigues da Silva; Anton Chigurb: o insólito vilão de No country for old men, de Maria Iranilde Almeida Costa Pinheiro e Jonas Magno Lopes Amorim; Estética de Glauber Rocha e as interfaces com o cinema documentário, de Rosselane Liz Giordani; A Inocência agreste: a representação do espaço no romance de Visconde de Taunay e na obra filmica de Walter Lima, de Erick Vinicius Mathias Leite; A representação feminina e as relações intersemióticas em Objetos Cortantes e Garota Exemplar, de Milena Ramos Pereira e Ana Carolina Negrão Berlini de Andrade; Do efeito de unheimlich à rememoração: o percurso narrativo da personagem Marion Post no filme A outra (1988), de Woody Allen, de Mariana Alice de Souza Miranda; Uma leitura alegórica do filme Paisagem na neblina, dirigido por Theo Angelopoulos, de Gong Li Cheng; Adaptação ecfrástica: sobre a presença da pintura no cinema, de Vanessa Luiza de Wallau, Cleber da Silva Luz; Os signos do realismo: da literatura ao cinema, de Flaubert às imagens digitais, de Jeferson Ferro; Materialização do hiper-real na matriæ: intermidialidade entre Baudrillard e Matrix, de Luiza da Silva Souza, Claudia Lorena Fonseca; Literatura, imagem e intermidialidade em Catálogo de perdas (2017), de João Anzanello Carrascoza e Juliana Monteiro Carrascoza, de Sandro Adriano da Silva; Intermidialidade em um passeio pela narrativa nos jogos de luta, de Alisson Preto Souza, Lis Yana de Lima Martinez; Pedra da memória corporalidades em confluências transatlânticas, de Rodrigo Birck Moreira e Izabela Fernandes de Souza; Um devir narrativo cinematográfico em O conto zero e outras histórias, de Sérgio Sant'anna, de Cristine Fickelscherer Mattos; e $A$ aliança de classes e o nascimento de uma nação em Cerimônia de casamento, de Marcos César de Paula Soares.

Na seção EDUCAÇÃO, temos: Da formação básica à prática docente: qual a percep̧̧ão do professor sobre a superdotação?, de Kelling Cabral Souto, Helena Carla Castro e Cristina Maria Carvalho Delou; e Medindo um território: a modalidade de Educação Mediada no contexto do NEaDUNI, de Higor Miranda Cavalcante e Beatriz Helena Dal Molin.

Por fim, na seção ENS AIOS E TEMAS INTERDISCIPLINARES, temos: Sociabilidade em tempos de quarentena: o Whats App como ferramenta de interação social durante a pandemia de COVID-19, de Fernanda de Fátima Fernandes Pereira, Daniele Ribeiro Fortuna e Renato da Silva.

Almejamos uma boa leitura!

Acir Dias da Silva Norival Bottos Jr 